\title{
Intangibles als wertvolle Ressource messen und steuern
}

\section{Schmalenbach-Tagung 2014, Köln}

Die Digitalisierung von Produkten, Dienstleistungen und Unternehmensprozessen schreitet voran und verschafft den immateriellen Ressourcen, den sogenannten Intangibles, einen immer größeren Stellenwert. Wie Unternehmen auf diese Entwicklung auf strategischer wie operativer Ebene reagieren sollten, wurde auf der diesjährigen Jahrestagung der Schmalenbach-Gesellschaft für Betriebswirtschaft e. V. am 27.03.2014 vor

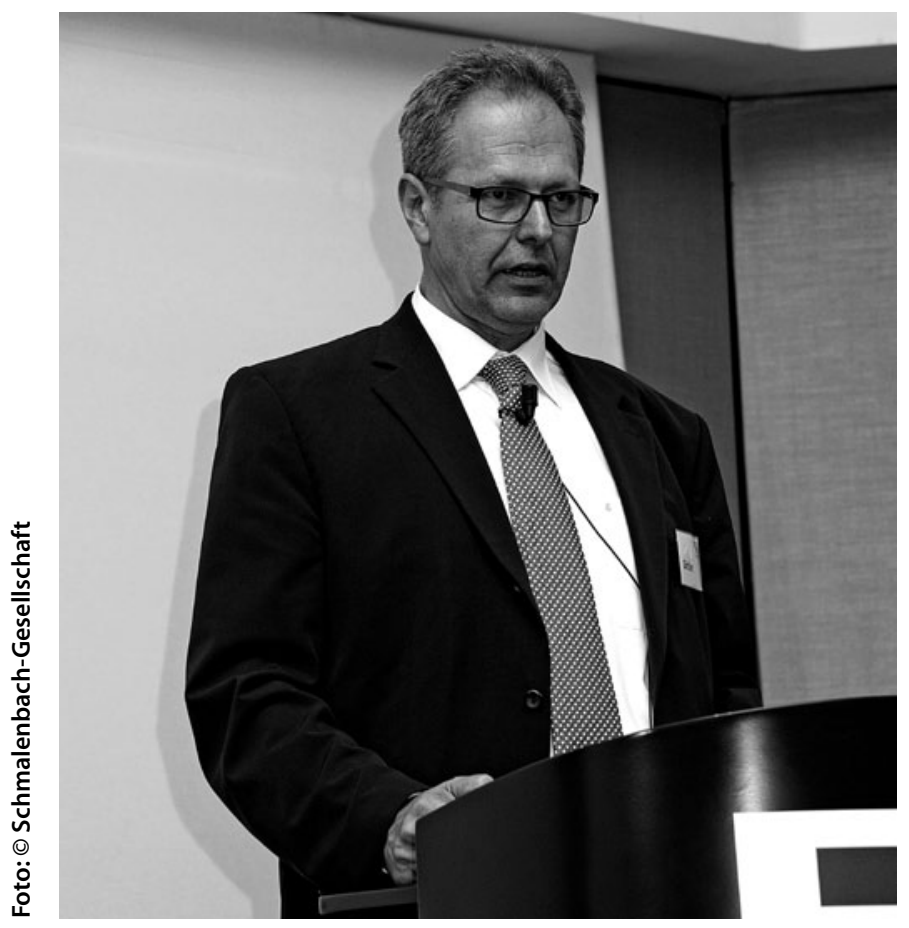

Prof. Dr. Thomas Günther spricht über die Steuerung von Intangibles als Herausforderung für das Controlling. rund 300 Teilnehmern diskutiert. Das aus Wissenschaft und Praxis hochrangig besetzte Podium sprach dabei viele interessante Themen aus Management, Marketing und Rechnungswesen an. Das Themenspektrum reichte von der Messung und Bewertung von Marken und Reputation über die Steuerung von F\&E-Projekten und die Aktivierung von F\&E-Leistungen bis hin zur Bilanzierung von immateriellen Werten und deren Bedeutung für die Unternehmenssteuerung.

Welchen Herausforderungen sich das Controlling in Bezug auf Intangibles stellen muss, erläuterte Professor Thomas Günther, Lehrstuhl für Betriebliches Rechnungswesen / Controlling, TU Dresden. Intangibles sind wertvoll und wertrelevant, häufig wertvoller und kostenintensiver als tangible Ressourcen. Aber wie lassen sich diese messen und steuern? Eine monetäre Steuerung ist nur begrenzt möglich. Vorzuziehen ist eine nicht-monetäre Steuerung, z. B. mittels Wissensbilanzen, nicht-finanziellen oder hybriden Kennzahlensystemen. Sie erfordert allerdings eine Anpassung der Systeme.

Dies mag einer der Gründe dafür sein, dass sich die dargestellten Methoden, wenngleich sie bereits existieren, in der deutschen Unternehmenslandschaft noch nicht überall durchgesetzt haben. Zum Beispiel enthält kaum ein Geschäftsbericht eine Wissensbilanz. Das Integrated Reporting, das ebenfalls auf nicht-monetärer Steuerung beruht, könnte diese Lücke füllen. Ob aber die Praxis dieses Konzept annehmen wird, bleibt das spannende Thema.

Vera Treitschke, Wiesbaden 